\title{
IL-17A-producing $T$ cells are associated with the progression of lung adenocarcinoma
}

\author{
ZHANG BAO $^{1 *}$, GUOHUA LU ${ }^{1 *}$, DAWEI CUI ${ }^{2}$, YINAN YAO $^{1}$, \\ GUANGDIE YANG $^{1}$ and JIANYING ZHOU ${ }^{1}$ \\ ${ }^{1}$ Department of Respiratory Medicine and ${ }^{2}$ Center of Clinical Laboratory, The First Affiliated Hospital, \\ College of Medicine, Zhejiang University, Hangzhou, Zhejiang 310003, P.R. China
}

Received January 17, 2016; Accepted February 20, 2016

DOI: $10.3892 /$ or.2016.4837

\begin{abstract}
Accumulating evidence has shown that $\mathrm{T}$ cells are crucial in shaping the tumor microenvironment and regulating tumor development. However, the roles of IL-17A-producing T cells (IL-17A ${ }^{+} \mathrm{CD} 4^{+}$Th17, $\mathrm{IL}^{+} 17 \mathrm{~A}^{+} \mathrm{CD} 8^{+} \mathrm{Tc} 17$ and $\mathrm{IL}-17 \mathrm{~A}^{+}$ $\gamma \delta \mathrm{T} 17$ cells) and related cytokines in the progression of lung cancer (LC) remain uncertain. Here, we found that the frequencies of both Th17 and $\gamma \delta \mathrm{T} 17$ cells in the peripheral blood of patients with lung adenocarcinoma (LA) were higher than those in healthy controls (HCs), whereas the frequency of Tc17 cells in the patients with LA was decreased. In addition, the frequencies of circulating Th17 and $\gamma \delta T 17$ cells, but not Tc17 cells, were positively associated with tumor invasion and metastasis. Furthermore, the major source of IL-17A production was Th17 cells, followed by Tc17 and $\gamma \delta T 17$ cells, in peripheral blood from patients with LA and HCs; but the percentages of Th17 and $\gamma \delta \mathrm{T} 17$ cells in total intracellular IL-17A ${ }^{+}$cells obtained from the patients with LC were higher than those from HCs. Moreover, the protein and corresponding mRNA levels of IL-17A, IL-23, IL-1 $\beta$, and TGF- $\beta 1$ were much higher in the patients with LA than those in HCs, and the levels of IL-17A in patients were positively correlated with numbers of both Th17 and $\gamma \delta \mathrm{T} 17$ cells, but not Tc17 cells. Finally, the frequencies of circulating Th17 and $\gamma \delta T 17$ cells, along with the levels of IL-17A, IL-23, IL-1 $\beta$, and TGF- $\beta 1$ were decreased in the patients with LA after tumor resection, whereas the frequency of circulating Tc17 cells was inversely increased in these patients. Our findings indicate that Th17, Tc17, $\gamma \delta T 17$ cells, and IL-17A-associated cytokines contribute
\end{abstract}

Correspondence to: Professor Jianying Zhou, Department of Respiratory Medicine, The First Affiliated Hospital, College of Medicine, Zhejiang University, Hangzhou, Zhejiang 310003, P.R. China

E-mail: zjyhz@zju.edu.cn

*Contributed equally

Key words: IL-17A-producing T cells, Th17 cells, Tc17 cells, $\gamma \delta \mathrm{T} 17$ cells, IL-17A, IL-23, lung cancer, lung adenocarcinoma to the development of LA and thus represent promising targets for therapeutic strategies.

\section{Introduction}

Lung cancer (LC) is currently the leading cause of cancer-related mortality among both males and females worldwide and was responsible for approximately 1.59 million deaths in $2012(1,2)$. LC has also been the number one cause of cancer-related deaths among patients with malignant tumors since 2008 in China (3). In addition, the mortality rate of LC in China has increased dramatically during the past three decades due to smoking and air pollution, imposing a huge economic burden on patients, medical professionals, and society (3).

LC is characterized by a series of hallmarks, such as tumor-promoting inflammation, avoidance of immune destruction, genomic instability, and induction of angiogenesis (4). Inflammatory responses contribute to the initiation, progression, and metastases of malignancies as proposed by Virchow in 1863, by promoting proliferative signaling, destabilizing genomic integrity, and inducing the invasion of cancer cells $(5,6)$. Chronic inflammation triggered by bacterial and viral infections, tobacco smoking, and chemicals suppress wound healing and tissue regenerative responses, promoting cancer development and progression, as described as 'wounds that do not heal' $(7,8)$. In addition, inflammation compromises genomic maintenance and repair pathways, inducing genomic instability $(6,9)$. Furthermore, cancer cells modulate inflammation by secreting soluble mediators and interfering with innate and adaptive immune cells, such as, macrophages, dendritic cells and lymphocytes (6). Multiple inflammatory mediators may trigger and maintain tumorigenesis individually or coordinately in the tumor microenvironment (6). The crosstalk between the inflammatory microenvironment and cancer cells controls and shapes tumor growth and metastasis (5-7).

Interleukin (IL)-17A, a proinflammatory cytokine discovered in 1993, induces tissue inflammation mainly by promoting expression of various cytokines, chemokines, antimicrobial peptides, and tissue-remodeling molecules (10-12). IL-17A exerts complicated functions in allergic, autoimmune, and malignant diseases, by targeting mesenchymal and myeloid cells $(10,13)$. Although originally linked to IL-17-producing $\mathrm{CD}^{+} \mathrm{T}$ helper (Th17) cells, a distinct 
T cell subtype different from Th1 and Th2 cells, IL-17A was subsequently found to be produced by several other immune cells, including IL-17A-producing $\gamma \delta \mathrm{T}(\gamma \delta \mathrm{T} 17)$ cells, IL-17Aproducing $\mathrm{CD}^{+} \mathrm{T}(\mathrm{Tc} 17)$ cells, natural killer $\mathrm{T}$ cells, and mast cells $(10,14,15)$. IL-17A-producing $\mathrm{T}$ cells and associated cytokines, such as IL-17, IL-23, and IL-1 $\beta$, have been shown to be involved in both inflammation and immune responses in various types of cancers including gastric, breast, prostate and hepatocellular cancer $(10,16-19)$. However, the roles of these $\mathrm{T}$ cells and associated cytokines are conflicting in various animal models and patients (10,20-22). IL-17-producing $\mathrm{T}$ cells have displayed both antitumor and protumor functions, due to their plasticity and functions in the tumor microenvironments (23). The numbers of circulating Th17 and $\gamma \delta \mathrm{T} 17$ cells were significantly higher in patients with gastric cancer than those in healthy controls (HCs) (16). On the contrary, data have shown that Th17 cells elicit antitumor effects, by promoting cytotoxic activities, enhancing Th1 response, and augmenting the expression of MHC antigens (24-26). In a murine model of LC, enhanced Th17 cells and overexpression of IL-17A stimulated tumor growth in the lungs $(27,28)$. Similarly, an increased number of intratumoral IL-17-positive cells in patients with LC was correlated with poor prognosis (29). However, a higher percentage of Tregs but a lower frequency of Th17 cells was found in malignant pleural effusion, as compared with those in parapneumonic effusion, and a higher ratio of Treg/Th17 cells in malignant pleural effusion was found to indicate a poor prognosis of patients with LC (30). Thus, the roles of IL-17A-producing T cells, especially Tc17 and $\gamma \delta T 17$ cells, and associated cytokines in the progression of $\mathrm{LC}$ remain to be defined.

In the present study, we investigated the frequencies of IL-17-producing T cells (Th17, Tc17 and $\gamma \delta \mathrm{T} 17$ cells) and levels of IL-17A-associated cytokines (IL-17A, IL-23, IL-1 $\beta$, and TGF- $\beta 1$ ) in patients with lung adenocarcinoma (LA) and HCs. We found that the frequencies of both Th17 and $\gamma \delta \mathrm{T} 17$ cells in the peripheral blood of patients with LA were higher than those in HCs and were positively associated with tumor invasion and metastasis, whereas the frequency of Tc17 cells in patients with LA was decreased. Furthermore, the major source of IL-17A production was Th17 cells in peripheral blood from both patients with LA and HCs. In addition, the protein and corresponding mRNA levels of IL-17A, IL-23, IL- $1 \beta$, and TGF- $\beta 1$ were much higher in patients with LA than those in HCs, and the levels of IL-17A were positively correlated with numbers of both Th17 and $\gamma \delta \mathrm{T} 17$ cells, but not Tc17 cells. Finally, the frequencies of circulating Th17 and $\gamma \delta T 17$ cells, along with levels of IL-17A, IL-23, IL-1 $\beta$, and TGF- $\beta 1$ were decreased in the patients with LA after tumor resection, whereas the frequency of circulating Tc17 cells was inversely increased in these patients. This study provides further insight into the association between IL-17A-producing $\mathrm{T}$ cells and progression of $\mathrm{LA}$, and offers promising targets for therapeutic strategies.

\section{Materials and methods}

Subjects. Forty patients, diagnosed with LA and admitted to the Department of Respiratory Medicine at the First Affiliated Hospital of Zhejiang University, and 35 HCs were enrolled
Table I. Characteristics of the patients with lung adenocarcinoma and healthy controls.

\begin{tabular}{|c|c|c|}
\hline Characteristics & Patients & Healthy controls \\
\hline \multicolumn{3}{|l|}{ Gender } \\
\hline Male & 27 & 24 \\
\hline Female & 13 & 11 \\
\hline \multicolumn{3}{|l|}{ Age (years) } \\
\hline Median & 53 & 54 \\
\hline Range & $36-77$ & $32-76$ \\
\hline \multicolumn{3}{|l|}{ Tumor grade } \\
\hline Well/moderate & 26 & \\
\hline Poor & 14 & \\
\hline \multicolumn{3}{|l|}{ Tumor stage } \\
\hline $\mathrm{T} 1$ & 19 & \\
\hline $\mathrm{T} 2$ & 13 & \\
\hline $\mathrm{T} 3$ & 0 & \\
\hline T4 & 8 & \\
\hline \multicolumn{3}{|l|}{ Node status } \\
\hline N0 & 21 & \\
\hline N1 & 9 & \\
\hline N2 & 7 & \\
\hline N3 & 3 & \\
\hline \multicolumn{3}{|l|}{ Metastasis } \\
\hline M0 & 34 & \\
\hline M1a/b & 6 & \\
\hline \multicolumn{3}{|l|}{ TNM stage } \\
\hline I & 16 & \\
\hline II & 10 & \\
\hline III & 8 & \\
\hline IV & 6 & \\
\hline
\end{tabular}

All patients were staged according to the 7th edition of the tumor, node, and metastasis (TNM) classification for lung cancer.

in this study from May 2014 to June 2015. All patients were histologically confirmed with LA by two pathologists. The patients were excluded if they had autoimmune diseases, immune compromised diseases, and pulmonary infections, if they were taking any drugs which affect immune responses, or if they had already received anticancer therapies including chemotherapy, radiotherapy, targeted therapy, surgery or immune therapy. The characteristics of the enrolled 40 patients and $35 \mathrm{HCs}$, are summarized in Table I. All cases with LA were staged according to the 7th edition of the tumor, node, and metastasis (TNM) classification for LC (31). The study was approved by the Ethics Committee of the First Affiliated Hospital of Zhejiang University, and informed consent was obtained from all patients and HCs.

Sample collection and processing. Peripheral blood samples were collected from the subjects before any regional or systemic anticancer treatments and re-collected from 15 patients after thoracic surgery. The fresh peripheral blood of all individuals 
was stored in heparin-coated tubes (BD Biosciences, San Jose, $\mathrm{CA}, \mathrm{USA}$ ) and centrifuged at $4,000 \mathrm{rpm}$ for $10 \mathrm{~min}$ at $4^{\circ} \mathrm{C}$. Then, the cell-free supernatants, allocated into 1.5-ml Eppendorf tubes, were frozen at $-80^{\circ} \mathrm{C}$ for the detection of cytokines (30). The cell pellets were re-suspended in saline for further analyses of flow cytometry and real-time quantitative reverse transcriptase polymerase chain reaction (qRT-PCR) (30).

Flow cytometric analysis. Human peripheral blood mononuclear cells (PBMCs), isolated from cell pellets using Ficoll-Hypaque density gradient centrifugation, were re-suspended in RPMI-1640 medium supplemented with $10 \%$ fetal bovine serum, $2 \mathrm{mM}$ glutamine, $100 \mathrm{U} / \mathrm{ml}$ penicillin and $100 \mu \mathrm{g} / \mathrm{ml}$ streptomycin (Invitrogen Life Technologies, Carlsbad, CA, USA). Next, they were stimulated for $5 \mathrm{~h}$ with $50 \mathrm{ng} / \mathrm{ml}$ phorbol 12-myristate 13-acetate (PMA; BioVision, Mountain View, CA, USA), $1 \mu \mathrm{g} / \mathrm{ml}$ ionomycin (Enzo Life Sciences, Inc., Farmingdale, NY, USA) and $500 \mathrm{ng} / \mathrm{ml}$ monensin (eBioscience, San Diego, CA, USA) in 24-well plates (16). To analyze IL-17A-producing T cells, stimulated PBMCs were stained with phycoerythrin (PE)-conjugated anti-human CD3, fluorescein isothiocyanate (FITC)-conjugated anti-human $\gamma \delta$ TCR, allophycocyanin (APC)-conjugated anti-human CD8, and Pacific Blue-conjugated anti-human CD4 antibodies at $4^{\circ} \mathrm{C}$ for $30 \mathrm{~min}$ (16). Then, the cells, fixed and permeabilized with IC fixation/permeabilization buffer (eBioscience), were intracellularly stained with PerCP-Cy5.5-conjugated anti-human IL-17 antibody according to the manufacturer's instructions (16). All antibodies used in the flow cytometric analysis were obtained from Biolegend (San Diego, CA, USA) and isotype-matched antibody controls were used in all procedures. Flow cytometric acquisition was performed using a FACSCalibur (BD Biosciences), and data were analyzed using FlowJo software, version 7.6.5 (TreeStar, Inc., San Carlos, CA, USA).

ELISA measurement of serum cytokines. The cell-free supernatants of all individuals were tested using ELISA kits according to the manufacturer's instructions (eBioscience), for cytokines including IL-17A, IL-23, IL-1 $\beta$, and TGF- $\beta 1$. All samples were tested in triplicate.

$q R T-P C R$. RNA samples were prepared from stimulated human PBMCs using TRIzol (Invitrogen Life Technologies) (16). cDNA was synthesized using reverse transcription reagent kits (Takara Biotechnolgy Co., Inc., Dalian, China) and real-time PCR was performed in triplicate using the QuantiFast $^{\text {TM }}$ SYBR Green PCR kit (Qiagen, Hilden, Germany) in an ABI 7500 analysis system (Applied Biosystems, Foster City, CA, USA) (16). The following primer pairs were used: IL-1 $\beta$ forward, 5'-CCACAGACCTTCCAGGAGAATG-3', and reverse, 5'-GTGCAGTTCAGTGATCGTACAGG-3'; IL-17A forward, 5'-CGGACTGTGATGGTCAACCTGA-3', and reverse, 5'-GCACTTTGCCTCCCAGATCACA-3'; IL-23p19 forward, 5'-GAGCCTTCTCTGCTCCCTGATA-3', and reverse, 5'-GACTGAGGCTTGGAATCTGCTG-3'; TGF- $\beta 1$ forward, 5'-CAGAAATACAGCAACAATTCCTGG-3', and reverse, 5'-TTGCAGTGTGTTATCCGTGCTGTC-3'; GAPDH forward, 5'-GGTCTCCTCTGACTTCAACA-3', and reverse, 5'-GTGAGGGTCTCTCTCTTCCT-3'. The data were analyzed by ABI 7500 software (Applied Biosystems).
Statistical analysis. Values are presented as means \pm SEM. Differences among groups were tested by one-way ANOVA. Differences between two groups were tested using non-paired Student's t-test. For non-parametric data, the Mann-Whitney $\mathrm{U}$ test was performed between groups. Correlations between values were determined using Spearman's correlation coefficient. Analysis was performed with SPSS statistical software (version 21.0; SPSS, Inc., Chicago, IL, USA), and P<0.05 was considered statistically significant.

\section{Results}

Characteristics of the subjects. Clinical characteristic of the 40 patients with LA and 35 HCs are summarized in Table I. The median age was 53 years (range, 36-77 years) in the patient group including 27 males and 13 females, and 54 years (range, 32-76 years) in the control group including 24 males and 11 females. Baseline characteristics were balanced between the two groups. In patients with LA, there were 26 cases with well/moderate differentiation and 14 cases with poor differentiation; 32 cases in tumor stage T1+T2 and 8 cases in T3+T4; 21 cases of node status N0 and 19 cases of node status $\mathrm{N} 1+\mathrm{N} 2+\mathrm{N} 3 ; 34$ cases in metastasis status $\mathrm{M} 0$ and 6 cases in M1a/b; 26 cases in stages I+II and 14 cases in TNM stages III+IV.

Frequency of circulating Th17, Tc17, and $\gamma \delta T 17$ cells in peripheral blood. To investigate the roles of IL-17A-producing $\mathrm{T}$ cells in the development of $\mathrm{LC}$, we first determined the frequencies of circulating Th17, Tc17, and $\gamma \delta T 17$ cells in the PBMCs obtained from all individuals. The frequencies of circulating Th17 and $\gamma \delta \mathrm{T} 17$ cells were considerably higher in patients with LA than those in the HCs (Fig. 1), but the frequency of circulating Tc17 cells was markedly lower in patients with LA than that in HCs (Fig. 1). In addition, there were no significant differences in the frequencies of circulating Th17, Tc17, and $\gamma \delta \mathrm{T} 17$ cells regarding tumor differentiation (well-moderate vs. poor); however, there were substantial differences between tumor invasion (T1+T2 vs. T3+T4), distant metastasis (M0 vs. M1a/b), and TNM stage (I+II and III+IV) (Fig. 2). The percentage of Th17 cells in patients with extensive tumor invasion (T3+T4) was higher than that in patients with $\mathrm{T} 1+\mathrm{T} 2$, while the percentage of $\mathrm{Tc} 17$ cells was low in patients with $\mathrm{T} 3+\mathrm{T} 4$ and the percentage of $\gamma \delta \mathrm{T} 17$ cells showed no difference in regards to tumor invasion (Fig. 2). The percentage of $\gamma \delta \mathrm{T} 17$ cells in patients with lymphatic metastasis $(\mathrm{N} 1+\mathrm{N} 2+\mathrm{N} 3)$ was significantly higher than that in patients with lymphatic metastasis (N0), while there were no differences in Th17 and Tc17 cells regarding lymphatic metastasis (Fig. 2). The percentage of Th17 and $\gamma \delta$ T17 cells in patients with distant metastasis (M1) were higher than that in patients without metastasis (M0), while the percentage of Tc17 cells was low in patients with distant metastasis (M1) (Fig. 2). The percentage of $\gamma \delta \mathrm{T} 17$ cells was higher in patients with III+IV stage than that in patients with I+II stage, while the percentage of Tc17 cells was low in patients with III+IV stage and there was no difference in the percentage of Th17 cells regarding TNM staging (Fig. 2). These findings suggest that a high percentage of circulating Th17 and $\gamma \delta T 17$ cells may contribute to the metastases of LA and indicate poor prognosis. 
A
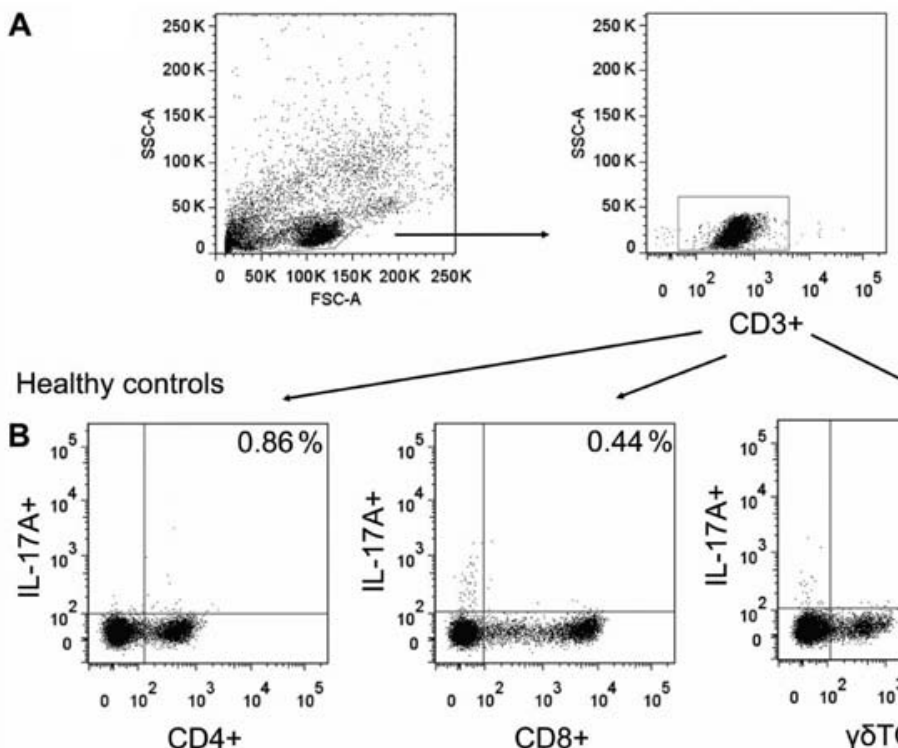

$\mathrm{CD} 3+$

Patients with lung cancer
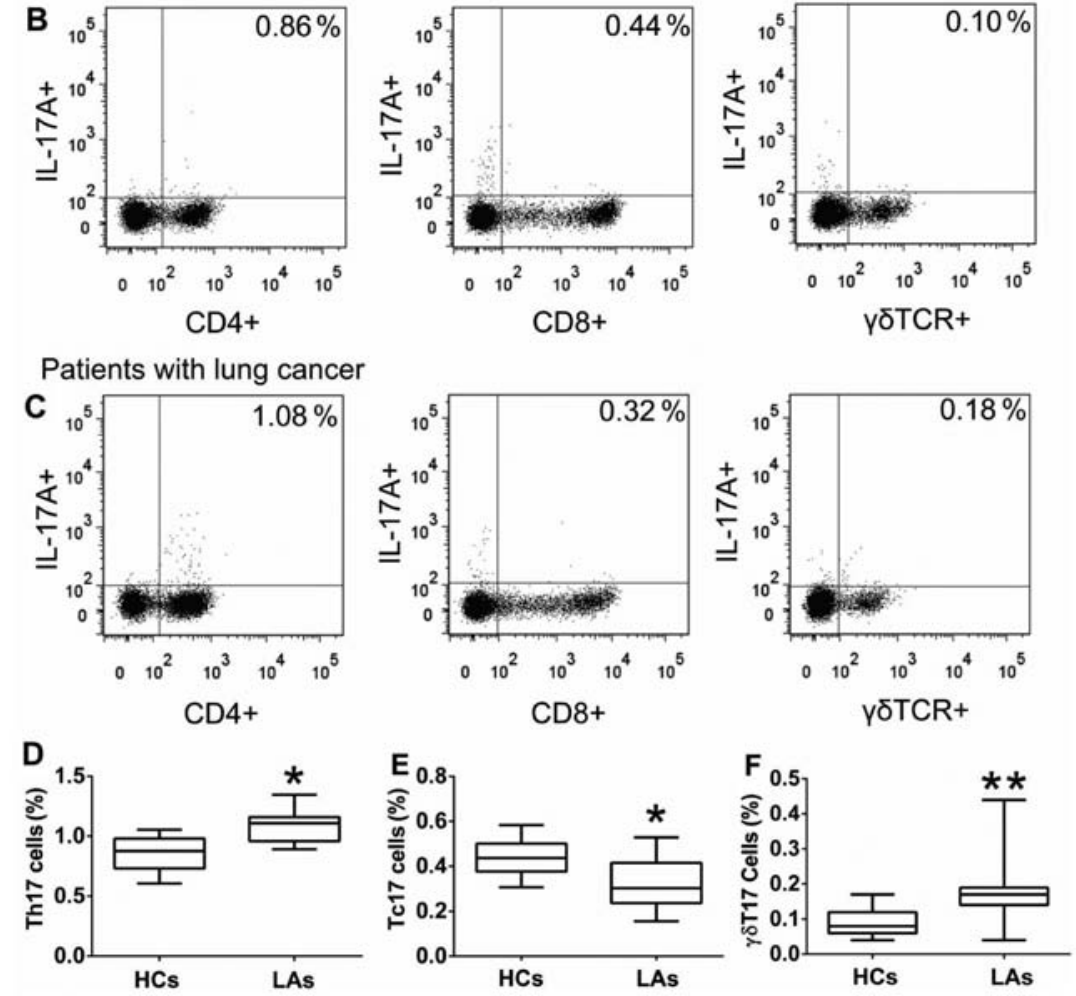

Figure 1. The frequency of circulating Th17, Tc17 and $\gamma \delta \mathrm{T} 17$ cells in all individuals. Peripheral blood mononuclear cells (PBMCs) obtained from patients with lung adenocarcinoma (LA) and healthy controls (HCs) were stained with labeled antibodies and analyzed using flow cytometric analysis. (A) PBMCs

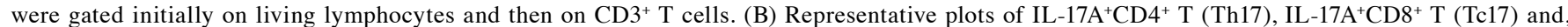
IL-17A ${ }^{+} \gamma \delta^{+} \mathrm{T}(\gamma \delta \mathrm{T} 17)$ cells in total $\mathrm{CD}^{+} \mathrm{T}$ cells from HCs. (C) Representative plots of Th17, Tc17, and $\gamma \delta \mathrm{T} 17$ cells in total CD3 $3^{+} \mathrm{T}$ cells from patients with LA. Comparison of (D) Th17, (E) Tc17, and (F) $\gamma \delta \mathrm{T} 17$ cells presented as percentages of total CD3 ${ }^{+} \mathrm{T}$ cells, between patients with LA and HCs. The data shown represent the means \pm SEM. ${ }^{~} \mathrm{P}<0.05,{ }^{* *} \mathrm{P}<0.01$ were considered to represent significant differences compared with HCs.

A

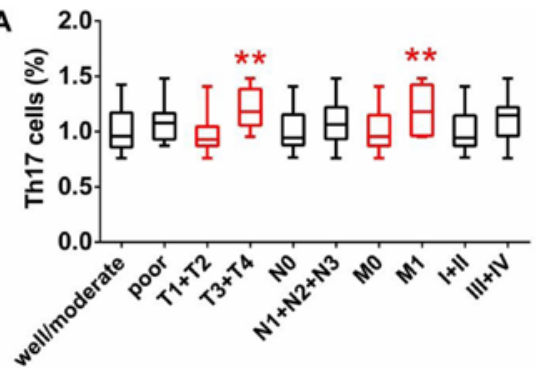

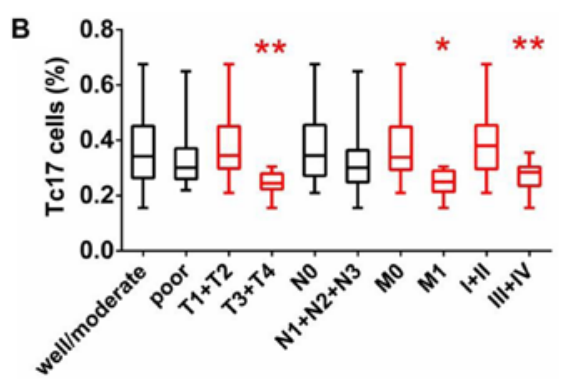

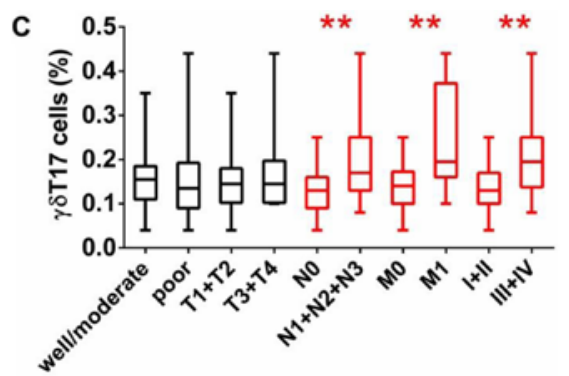

Figure 2. Analysis of circulating Th17, Tc17 and $\gamma \delta \mathrm{T} 17$ cells in patients with different tumor characteristics. The percentages of (A) Th17, (B) Tc17 and (C) $\gamma \delta \mathrm{T} 17$ cells in patients with lung adenocarcinoma (LA) were compared according to tumor differentiation (good/moderate vs. poor), tumor invasion (T1+T2 vs. T3+T4), lymph node status (N0 vs. N1+N2+N3), metastasis (M0 vs. M1), and TNM stage (I+II and III+IV); The data shown represent the means \pm SEM. ${ }^{*} \mathrm{P}<0.05,{ }^{* *} \mathrm{P}<0.01$ were considered to represent significant differences.

The main $T$ cells secreting IL-17A in peripheral blood. To further explore the main $\mathrm{T}$ cells secreting IL-17A in the peripheral blood, we measured the frequencies of circulating Th17, Tc17, and $\gamma \delta T 17$ cells in gated intracellular IL-17A cells 

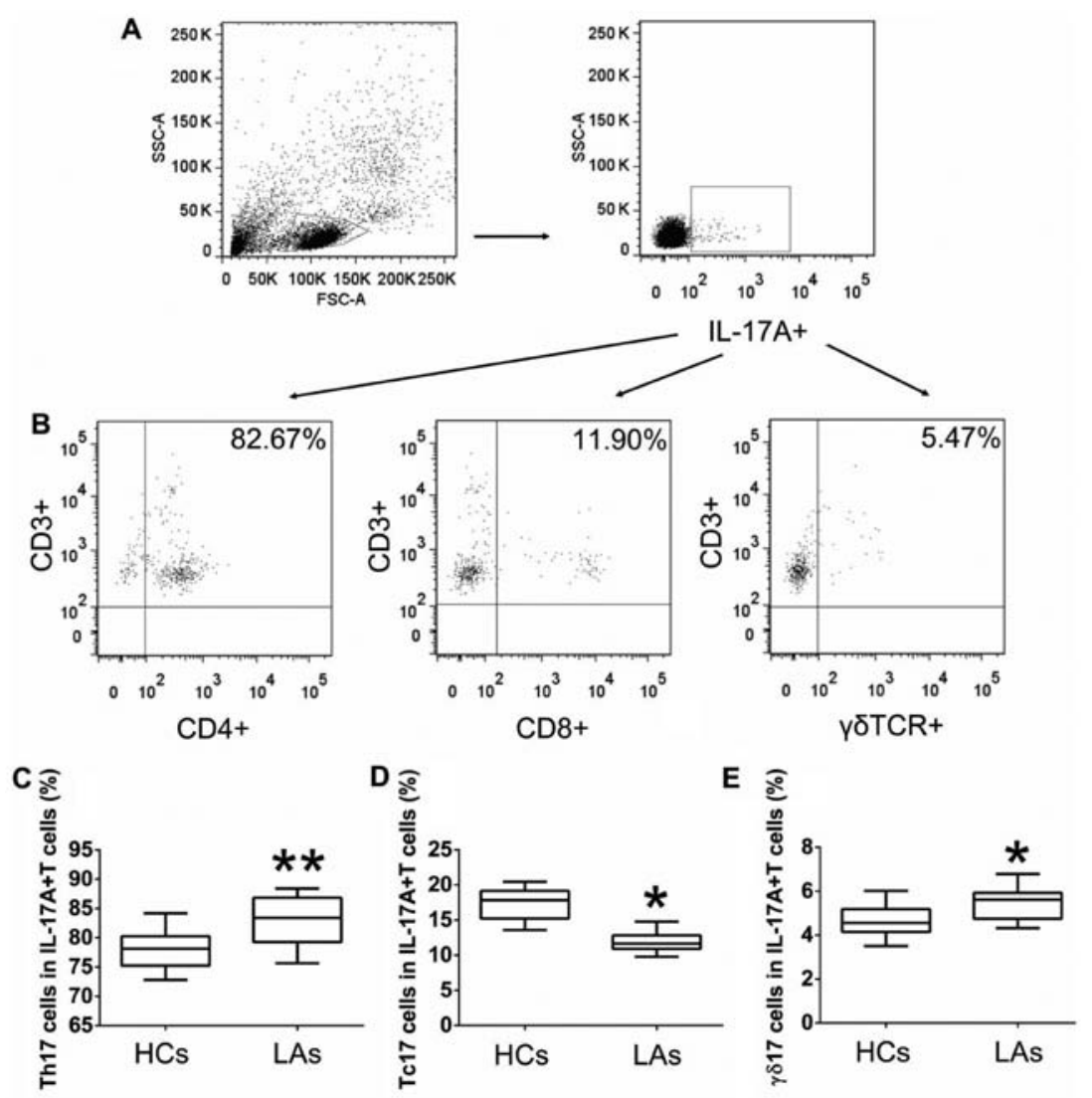

Figure 3. Percentages of Th17, Tc17, and $\gamma \delta T 17$ cells in IL-17A ${ }^{+}$cells. Peripheral blood mononuclear cells (PBMCs) obtained from patients with lung adenocarcinoma (LA) and healthy controls (HCs) were stained with labeled antibodies and analyzed using flow cytometric analysis. (A) PBMCs were gated initially on living lymphocytes and then on intracellular IL-17A. (B) Representative plots of Th17, Tc17, and $\gamma \delta \mathrm{T} 17$ cells in IL-17A ${ }^{+}$cells from patients with LA. Comparison of (C) Th17, (D) Tc17, and (E) $\gamma \delta \mathrm{T} 17$ cells presented as percentages of total IL-17A ${ }^{+}$cells between patients with LA and HCs. The data shown represent the means \pm SEM. ${ }^{*} \mathrm{P}<0.05,{ }^{* *} \mathrm{P}<0.01$ were considered to represent significant differences.
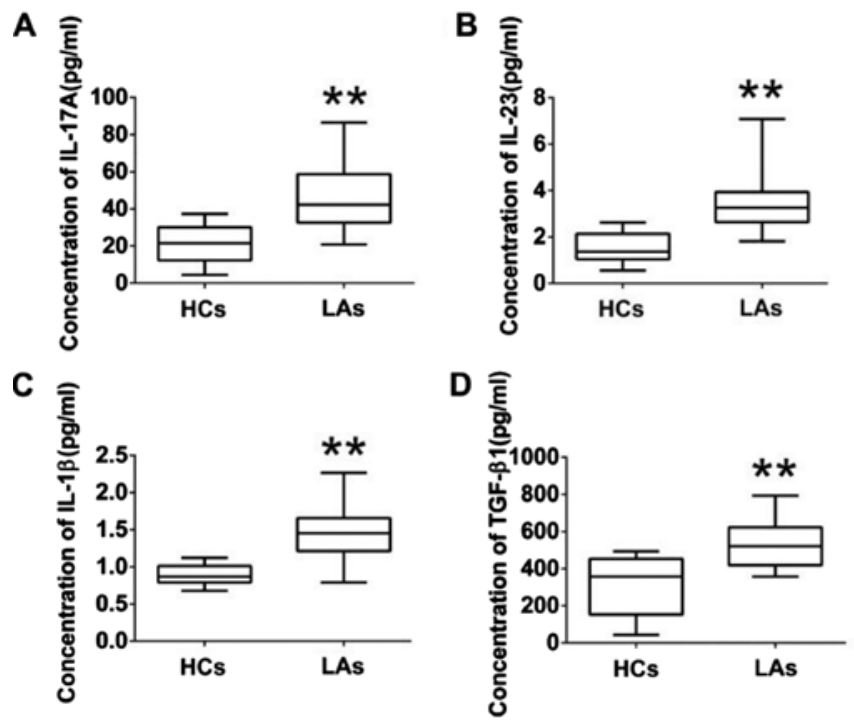

Figure 4. Protein levels of IL-17A and associated cytokines (IL-23, IL-1 $\beta$ and TGF- $\beta 1$ ) in serum. Comparison of (A) IL-17A, (B) IL-23, (C) IL-1 $\beta$, and (D) TGF- $\beta 1$ concentration between patients with lung adenocarcinoma (LA) and healthy controls (HCs). The data shown represent the means \pm SEM. " $\mathrm{P}<0.05$, ${ }^{* *} \mathrm{P}<0.01$ were considered to represent significant differences.

obtained from patients with LA and HCs by flow cytometric analysis. The highest population among the intracellular IL-17A ${ }^{+} \mathrm{T}$ cells in both patients with LA and HCs was circulating Th17 cells, followed by Tc17 and $\gamma \delta T 17$ cells (Fig. 3).
Furthermore, the percentages of Th17 and $\gamma \delta T 17$ cells in the total intracellular IL-17 $\mathrm{A}^{+}$cells obtained from patients with LA were higher than those from the HCs, while the percentage of intracellular IL-17A $\mathrm{A}^{+}$cells represented by circulating Tc17 

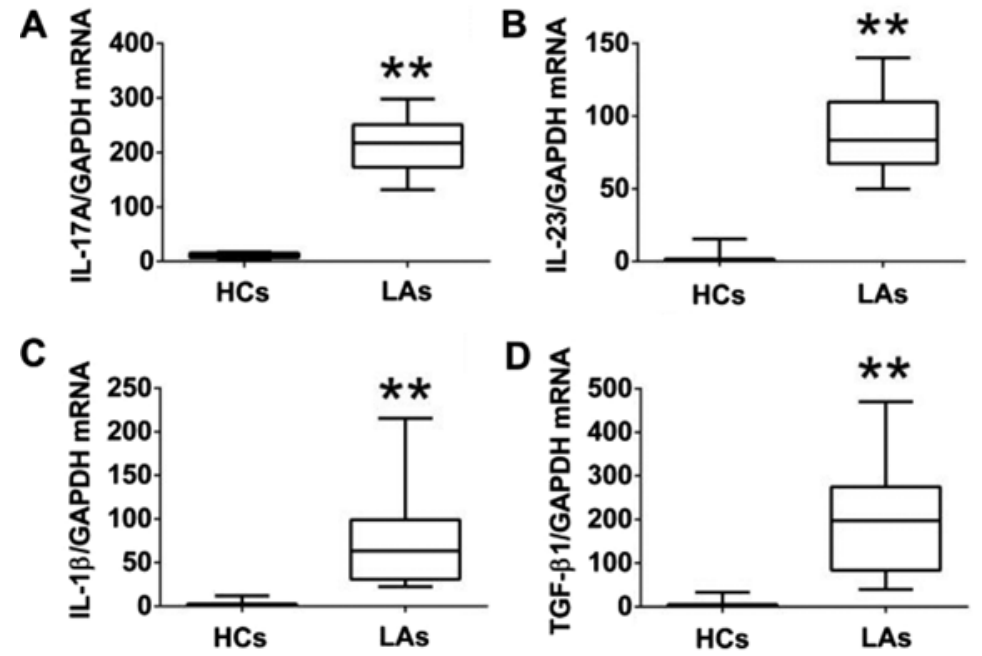

Figure 5. The mRNA levels of IL-17A and associated cytokines (IL-23, IL-1 $\beta$ and TGF- $\beta 1$ ) in PBMCs. Comparison of (A) IL-17A, (B) IL-23, (C) IL-1 $\beta$, and (D) TGF- $\beta 1$ mRNA levels between patients with lung adenocarcinoma (LA) and healthy controls (HCs). The data shown represent the means \pm SEM. ${ }^{* *} \mathrm{P}<0.01$ was considered to represent significant differences.
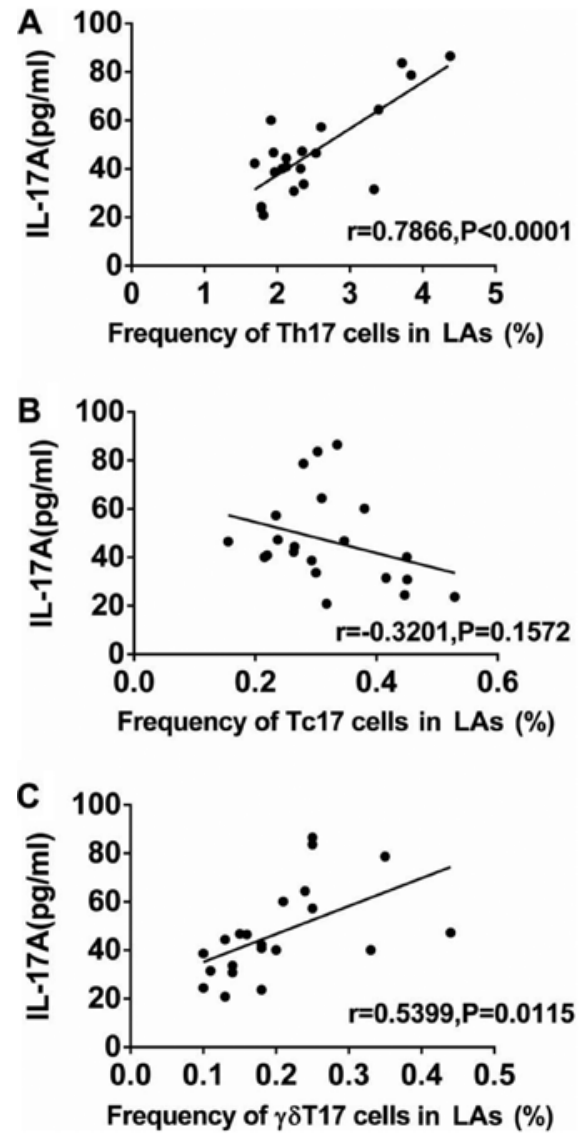

Figure 6. Association between IL-17A protein levels and frequencies of circulating Th17, Tc17 and $\gamma \delta$ T17 cells in patients with lung adenocarcinoma (LA). (A) Association between the protein level of IL-17A and the frequencies of circulating (A) Th17, (B) Tc17, and (C) $\gamma \delta T 17$ cells. $P<0.05$ was considered to represent significant difference.

cells was low in patients with LA compared to that in patients with LCs (Fig. 3). These data indicated that the main source of intracellular IL-17A in the peripheral blood was Th17 cells for both the patients and the $\mathrm{HCs}$, and that circulating IL-17A ${ }^{+}$ $\mathrm{T}$ cells and IL-17A play key roles in the initiation and progression of LC.

Analysis of IL-17A and associated cytokines in peripheral blood. To further explore the functions of IL-17A-producing $\mathrm{T}$ cells, the protein levels of IL-17A and associated cytokines (IL-23, IL-1 $\beta$, and TGF- $\beta 1$ ) in serum and their mRNA levels in PBMCs from both the patients and the HCs were measured by ELISA and qRT-PCR. The protein levels of IL-17A, IL-23, IL- $1 \beta$, and TGF- $\beta 1$ in the serum of patients with LA were much higher than those in the HCs (Fig. 4). Similarly, the mRNA levels of IL-17A IL-23, IL-1 $\beta$, and TGF- $\beta 1$ in PBMCs of patients with LA were markedly higher than those in the HCs (Fig. 5). In addition, we analyzed the association between the levels of IL-17A and the frequencies of Th17, Tc17 and $\gamma \delta \mathrm{T} 17$ cells in patients with LA. The expression of IL-17A in serum from patients was positively associated with the frequencies of Th17 and $\gamma \delta T 17$ cells, but was not related to the frequency of Tc17 cells (Fig. 6).

Alterations of IL-17A-producing T cells and IL-17A-associated cytokines in patients with LA after thoracic surgery. To explore the effects of tumor burden on IL-17A-producing T cells, we also measured both the frequencies of circulating Th17, Tc17, and $\gamma \delta T 17$ cells and levels of IL-17A and associated cytokines in 15 patients with LA, who received surgery, at 1 month after the resection. The frequencies of Th17 and $\gamma \delta T 17$ cells in the patients with LA were markedly decreased after surgery, while the frequency of Tc17 was significantly increased after surgery (Fig. 7A). Furthermore, both the protein levels of IL-17A IL-23, IL-1 $\beta$, and TGF- $\beta 1$ in serum and the corresponding mRNA levels in PBMCs were markedly decreased in the patients with LA after surgery (Fig. 7B and C). These data suggested that tumor resection resulted in the alteration of IL-17A-producing cells, IL-17A-associated cytokines, and the tumor-related microenvironment. 

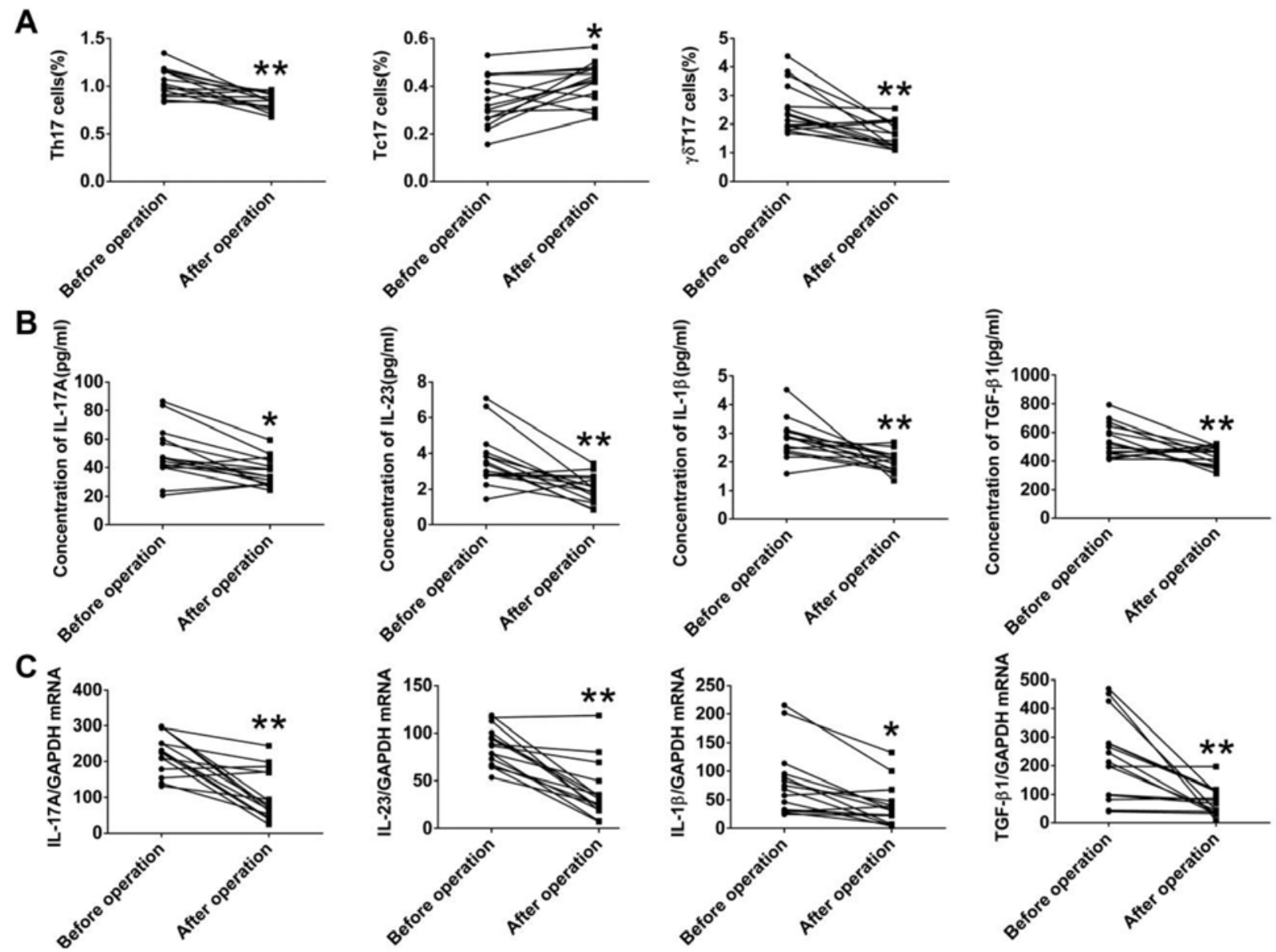

Figure 7. Alterations in IL-17A-producing T cells and IL-17A-associated cytokines in patients with lung adenocarcinoma (LA) after surgery. (A) Alterations in Th17, Tc17 and $\gamma \delta$ T17 cells in patients with LA after surgery. (B) Alterations in protein levels of IL-17A and associated cytokines (IL-23, IL-1 $\beta$ and TGF- $\beta 1$ ) in patients with LA after thoracic surgery. (C) Alterations of mRNA levels of IL-17A, IL-23, IL-1 $\beta$ and TGF- $\beta 1$ in patients with LA after surgery. "P<0.05, ${ }^{* *} \mathrm{P}<0.01$ were considered to represent significant differences.

\section{Discussion}

Evidence has shown the dual roles of $\mathrm{T}$ cells and associated cytokines in the initiation, progression, and metastasis of LC. The present study investigated the frequencies of IL-17A-producing cells (Th17, Tc17, and $\gamma \delta \mathrm{T} 17$ cells), and expression levels of IL-17-associated cytokines in patients with LA and HCs. We found that the frequencies of circulating Th17 and $\gamma \delta \mathrm{T} 17$ cells, and the protein and corresponding mRNA levels of IL-17A, IL-23, IL-1 $\beta$, and TGF- $\beta 1$ in the peripheral blood of patients with LA were higher than those in the HCs, whereas the frequency of Tc17 cells in patients with LA was decreased. Moreover, the frequencies of circulating Th17 and $\gamma \delta \mathrm{T} 17$ cells, along with the levels of IL-17A, IL-23, IL-1 $\beta$, and TGF- $\beta 1$ were decreased in patients with LA after tumor resection. Our findings suggest that Th17, $\gamma \delta \mathrm{T} 17$, Tc17 cells, and IL-17A-associated cytokines contribute to the development of LA and thus represent promising targets for therapeutic strategies.

Th17 cells were originally discovered to promote inflammatory responses in autoimmune diseases and act in host defenses against microbes $(32,33)$. Recently, their functions in the initiation and development of cancers have been extensively studied (34). However, the roles of Th17 cells and its main cytokine, IL-17A, in carcinogenesis are still controversial (35). Accumulation of tumor-infiltrating Th17 cells have been found in a variety of cancers, including gastric, hepatocellular, breast, and LCs, and contributed to poor patient prognosis $(28,36-38)$. Cytokines secreted by cancer cells, such as RANTES, MCP1, IL-6, IL-1 $\beta$, and CCL 20, contribute to the differentiation and expansion of Th17 cells, in the tumor microenvironment $(35,39)$. Moreover, Th17 cells and IL-17 resulted in the recruitment of $\mathrm{Gr}-\mathrm{I}^{+} \mathrm{CD} 11 \mathrm{~b}^{+}$myeloid cells, promoting the inflammation and tumor growth in a mouse model with oncogenic K-ras mutation expressed only in the lungs (28). Smoking-mediated Th17 inflammation by induction of osteopontin and IL-17A deficiency attenuated smoking-induced emphysema in mice (40). In contrast, elevated Th17 cells or a high ratio of Th17/Treg, in malignant pleural effusion, partially promoted by chemokines, predicted a good prognosis in patients with LC $(30,41)$. Th17 cells may promote the recruitment of dendritic cells and subsequent activation of $\mathrm{CD} 8^{+} \mathrm{T}$ cells in tumors, exerting antitumor immunity (26). In IL-17-deficient mice, tumor growth and lung metastasis were augmented, accompanied by decreased natural killer cells and $\mathrm{T}$ cells, suggesting the protective roles of endogenous IL-17 and Th17 in tumors (25). Consistent with previous studies, our results demonstrated that the frequency of circulating 
Th17 cells was increased in the patients with LA, and was associated with tumor invasion and metastasis, indicating the pro-tumoral roles of Th17 cells in the initiation and progression of LA (42). It was also confirmed that Th17 cells were the main source of IL-17A in human peripheral blood in both patients with LA and HCs. However, the mechanisms involved in the accumulation of Th17 cells in the tumor microenvironment are still unknown, and Th17 cells could be induced, expanded, or converted from other T cells.

Tc17 cells, a minor subset of $\mathrm{CD}^{+} \mathrm{T}$ cells characterized by the production of IL-17, play various roles in infection, cancers and autoimmune diseases $(43,44)$. Although most of the knowledge concerning the differentiation and plasticity of Tc17 cells stems from autoimmune diseases, emerging evidence has also shown that Tc17 cells are associated with the development of cancers in both animal models and humans (43). In patients with hepatocellular carcinoma, tumoractivated monocytes triggered the proliferation of Tc17 cells at the edge of invading tumors, by a set of proinflammatory cytokines (45). In patients with uterine cervical cancer, high levels of Tc17 cells were found in both the peripheral blood and in cervical tissues, and were involved in the metastases of pelvic lymph nodes and tumor vasculogenesis (46). Notably, adoptive transfer of tumor-specific Tc17 cells led to the regression of melanoma in mice by the recruitment of neutrophils and induction of chemokines, and elicited antitumor immunity, which was reversed by the blocking of the inducible costimulator pathway (47-49). The numbers of both $\mathrm{CD}^{+}$and $\mathrm{CD} 8^{+} \mathrm{T}$ cells were significantly elevated in lung tumor tissues compared with $\mathrm{HCs}$, and were positively related to the staging of cancers (50). In spite of some functional similarities shared with Th17 cells, it has become gradually clear that Tc17 cells are a distinct subset of $\mathrm{T}$ cells regarding differentiation, development, and plasticity. Contrary to Th17 cells, the frequency of circulating Tc17 cells was reduced in the patients with LA, especially those with tumor invasion and distant metastasis. These results are consistent with data from patients with thyroid tumors or gastric carcinoma, suggesting that Tc17 cells may exhibit some antitumor activities in lung carcinoma and Th17 cells may suppress the development of $\mathrm{Tc} 17$ in the tumor microenvironment $(16,51)$.

$\gamma \delta \mathrm{T}$ cells, compared with conventional $\alpha \beta \mathrm{T}$ cells, exhibit distinct and versatile functions by recognition of non-peptide antigens, production of proinflammatory cytokines (IL-17, interferon- $\gamma$, and TNF- $\alpha$ ), and interaction with activation of adaptive immune cells $(21,52)$. $\gamma \delta T 17$ cells, the primary source of IL-17 in the early stage of some diseases and one of the pivotal players in immune surveillance, display diverse responses to tumors $(20,53)$. In patients with colorectal cancers, $\gamma \delta \mathrm{T} 17$ cells were found to be a major source of IL-17, related to the expansion of myeloid-derived suppressor cells, and positively associated with tumor stages (54). Murine $\gamma \delta T 17$ cells also mobilized small peripheral macrophages, which expressed proangiogenic and proinflammatory mediators, and promoted ovarian cancer growth in vivo (55). Recently, in a murine model of breast cancer, $\gamma \delta \mathrm{T} 17$ cells resulted in expansion and polarization of specific neutrophils which subsequently inhibited cytotoxic $\mathrm{CD}^{+}$lymphocytes, and led to pulmonary and lymph nodal metastases, indicating a cooperative mechanism among $\gamma \delta \mathrm{T} 17$ cells, cytotoxic T cells and neutrophils in the metastatic microenvironment (18). In our study, $\gamma \delta \mathrm{T} 17$ cells were the third source of IL-17A, which were consistent with gastric patients but not with colorectal cancers $(16,54)$. In addition, increased frequency of $\gamma \delta T 17$ cells was found in patients with LA and was positively related to the metastasis and staging of cancers, and was markedly decreased after the resection of the tumor. The prevalence and variety of $\gamma \delta T 17$ cells in patients with LA were very similar with those of Th17 cells, suggesting these two IL17-producting T cells may collaboratively promote pulmonary carcinogenesis.

In response to stress, injury, and pathogenic stimuli, IL-17-associated cytokines, including IL-23, IL-1 $\beta$, and TGF- $\beta 1$, drive the differentiation of naïve $\mathrm{T}$ cells into IL-17-producing T cells $(14,43,56)$. IL-23 further induces the production of IL-17 by Th17 and $\gamma \delta \mathrm{T}$ cells, and promotes tumor growth (22,57). IL-17 targets myeloid and mesenchymal cells, and induces tissue inflammation by promoting the expression of proinflammatory cytokines, chemokines, and antimicrobial peptides (10). In addition, IL-17 resulted in the infiltration of myeloid-derived suppressor cells and angiogenesis in tumors, and contributes to the tumor-promoting microenvironments in mice $(58,59)$. Elevated levels of IL-17 were found in patients with gastric, colorectal and prostatic cancers, and are associated with poor prognosis (60). Recently, increased levels of IL-23, IL-1 $\beta$, and IL-17A were found in gastric patients and were positively related to tumor invasion and metastasis (24). In experimental silicosis, IL-17A produced by both Th17 and $\gamma \delta \mathrm{T} 17$ cells was required for acute pulmonary inflammation and injury, but not chronic responses and fibrosis (61). Our study showed that both the mRNA and protein levels of IL-17A IL-23, IL-1 $\beta$, and TGF- $\beta 1$ in PBMCs of patients with LA were markedly higher than those in the HCs. In addition, the expression of IL-17A in serum was positively associated with the number of Th17 and $\gamma \delta T 17$ cells, but not Tc17 cells. Results indicated that these inflammatory cytokines contribute to the proliferation of Th17 and $\gamma \delta \mathrm{T} 17$ cells, and the progression of $\mathrm{LC}$ in the tumor microenvironment.

We further explored the effects of the resection of lung tumors on the alterations of IL-17-producing $\mathrm{T}$ cells and inflammatory cytokines. Notably, after surgery in patients with LA, the frequencies of Th17 and $\gamma \delta T 17$ cells, and cytokines including IL-17A IL-23, IL- $1 \beta$, and TGF- $\beta 1$ were markedly reduced, whereas the frequency of Tc17 cells recovered, suggesting that removal of tumors may restore immune hemostasis and surveillance, and IL-17-producing cells may be critical to tumor progression.

In conclusion, our data demonstrated that the frequencies of circulating Th17 and $\gamma \delta T 17$ cells, and the protein and corresponding mRNA levels of IL-17A, IL-23, IL-1 $\beta$, and TGF- $\beta 1$ in the peripheral blood of patients with LA were higher than those in HCs, whereas the frequency of Tc17 cells in patients with LA was decreased. In addition, Th17 cells were the major source of IL-17A in patients with LA and HCs. Moreover, the frequencies of circulating Th17 and $\gamma \delta \mathrm{T} 17$ cells, along with levels of IL-17A, IL-23, IL-1 $\beta$, and TGF- $\beta 1$ were decreased in the patients with LA after tumor resection. Our data suggest that Th17, $\gamma \delta \mathrm{T} 17$ and Tc17 cells, and IL-17A-associated cytokines play pivotal roles in the crosstalk between tumor-related inflammation and immunity, and contribute to the development of LC. In the future, a better understanding of the distribution 
and cooperation among IL-17-producing T cells would provide us with a rationale for novel anticancer strategies.

\section{Acknowledgements}

This study was supported by the National Natural Science Foundation of China (nos. 81472171, and 81300009), the Major Project of the Science Technology Department of Zhejiang Province, China (no. 2012C13022-2), the Zhejiang Provincial Natural Science Foundation of China (no. LY14H010002), the Key Personnel Grant of Zhejiang Medicine and Health Platform (no. 2012RCA025), and the Grant for Returned Overseas Chinese Scholars of the Personnel Department of Zhejiang Province (no. J20120565).

\section{References}

1. Islami F, Torre LA and Jemal A: Global trends of lung cancer mortality and smoking prevalence. Transl Lung Cancer Res 4: 327-338, 2015.

2. Siegel RL, Miller KD and Jemal A: Cancer statistics, 2016. CA Cancer J Clin 66: 7-30, 2016.

3. She J, Yang P, Hong Q and Bai C: Lung cancer in China: Challenges and interventions. Chest 143: 1117-1126, 2013.

4. Hanahan D and Weinberg RA: Hallmarks of cancer: The next generation. Cell 144: 646-674, 2011.

5. Balkwill $F$ and Mantovani A: Inflammation and cancer: Back to Virchow? Lancet 357: 539-545, 2001.

6. Elinav E, Nowarski R, Thaiss CA, Hu B, Jin C and Flavell RA: Inflammation-induced cancer: Crosstalk between tumours, immune cells and microorganisms. Nat Rev Cancer 13: 759-771, 2013.

7. Grivennikov SI, Greten FR and Karin M: Immunity, inflammation, and cancer. Cell 140: 883-899, 2010.

8. Dvorak HF: Tumors: Wounds that do not heal. Similarities between tumor stroma generation and wound healing. N Engl J Med 315: 1650-1659, 1986.

9. Pálmai-Pallag T and Bachrati CZ: Inflammation-induced DNA damage and damage-induced inflammation: A vicious cycle. Microbes Infect 16: 822-832, 2014.

10. $\mathrm{Xu} \mathrm{S}$ and Cao X: Interleukin-17 and its expanding biological functions. Cell Mol Immunol 7: 164-174, 2010.

11. Yao Z, Fanslow WC, Seldin MF, Rousseau AM, Painter SL, Comeau MR, Cohen JI and Spriggs MK: Herpesvirus Saimiri encodes a new cytokine, IL-17, which binds to a novel cytokine receptor. Immunity 3: 811-821, 1995.

12. Rouvier E, Luciani MF, Mattéi MG, Denizot F and Golstein P CTLA-8, cloned from an activated $\mathrm{T}$ cell, bearing AU-rich messenger RNA instability sequences, and homologous to a herpesvirus saimiri gene. J Immunol 150: 5445-5456, 1993.

13. Iwakura $Y$, Ishigame $H$, Saijo $S$ and Nakae $S$ : Functional specialization of interleukin-17 family members. Immunity 34: 149-162, 2011.

14. Cua DJ and Tato CM: Innate IL-17-producing cells: The sentinels of the immune system. Nat Rev Immunol 10: 479-489, 2010.

15. Aggarwal S, Ghilardi N, Xie MH, de Sauvage FJ and Gurney AL: Interleukin-23 promotes a distinct CD4 $\mathrm{T}$ cell activation state characterized by the production of interleukin-17. J Biol Chem 278: 1910-1914, 2003.

16. Zhong F, Cui D, Tao H, Du H and Xing C: IL-17A-producing $\mathrm{T}$ cells and associated cytokines are involved in the progression of gastric cancer. Oncol Rep 34: 2365-2374, 2015.

17. Ma S, Cheng Q, Cai Y, Gong H, Wu Y, Yu X, Shi L, Wu D, Dong $\mathrm{C}$ and Liu H: IL-17A produced by $\gamma \delta \mathrm{T}$ cells promotes tumor growth in hepatocellular carcinoma. Cancer Res 74 $1969-1982,2014$

18. Coffelt SB, Kersten K, Doornebal CW, Weiden J, Vrijland K, Hau CS, Verstegen NJ, Ciampricotti M, Hawinkels LJ, Jonkers J, et al: IL-17-producing $\gamma \delta \mathrm{T}$ cells and neutrophils conspire to promote breast cancer metastasis. Nature 522 345-348, 2015.

19. Zhang Q, Liu S, Ge D, Zhang Q, Xue Y, Xiong Z, Abdel-Mageed AB, Myers L, Hill SM, Rowan BG, et al: Interleukin-17 promotes formation and growth of prostate adenocarcinoma in mouse models. Cancer Res 72: 2589-2599, 2012.
20. Silva-Santos B, Serre K and Norell H: $\gamma \delta$ T cells in cancer. Nat Rev Immunol 15: 683-691, 2015.

21. Patil RS, Bhat SA, Dar AA and Chiplunkar SV: The Jekyll and Hyde story of IL17-producing $\gamma \delta T$ cells. Front Immunol 6: 37 , 2015.

22. Wang $\mathrm{K}$ and Karin M: The IL-23 to IL-17 cascade inflammation-related cancers. Clin Exp Rheumatol 33 (Suppl 92): S87-S90, 2015

23. Shalapour S and Karin M: Immunity, inflammation, and cancer: An eternal fight between good and evil. J Clin Invest 125: 3347-3355, 2015.

24. Hemdan NY: Anti-cancer versus cancer-promoting effects of the interleukin-17-producing T helper cells. Immunol Lett 149: 123-133, 2013.

25. Kryczek I, Wei S, Szeliga W, Vatan L and Zou W: Endogenous IL-17 contributes to reduced tumor growth and metastasis. Blood 114: 357-359, 2009

26. Martin-Orozco N, Muranski P, Chung Y, Yang XO, Yamazaki T, Lu S, Hwu P, Restifo NP, Overwijk WW and Dong C: T helper 17 cells promote cytotoxic $\mathrm{T}$ cell activation in tumor immunity. Immunity 31: 787-798, 2009.

27. Xu B, Guenther JF, Pociask DA, Wang Y, Kolls JK, You Z, Chandrasekar B, Shan B, Sullivan DE and Morris GF: Promotion of lung tumor growth by interleukin-17. Am J Physiol Lung Cell Mol Physiol 307: L497-L508, 2014.

28. Chang SH, Mirabolfathinejad SG, Katta H, Cumpian AM, Gong L, Caetano MS, Moghaddam SJ and Dong C: T helper 17 cells play a critical pathogenic role in lung cancer. Proc Natl Acad Sci USA 111: 5664-5669, 2014

29. Chen X, Wan J, Liu J, Xie W, Diao X, Xu J, Zhu B and Chen Z: Increased IL-17-producing cells correlate with poor survival and lymphangiogenesis in NSCLC patients. Lung Cancer 69: 348-354, 2010.

30. Yang G, Li H, Yao Y, Xu F, Bao Z and Zhou J: Treg/Th17 imbalance in malignant pleural effusion partially predicts poor prognosis. Oncol Rep 33: 478-484, 2015.

31. Goldstraw P, Crowley J, Chansky K, Giroux DJ, Groome PA, Rami-Porta R, Postmus PE, Rusch V, Sobin L; International Association for the Study of Lung Cancer International Staging Committee, et al: The IASLC Lung Cancer Staging Project: proposals for the revision of the TNM stage groupings in the forthcoming (seventh) edition of the TNM Classification of malignant tumours. J Thorac Oncol 2: 706-714, 2007.

32. Muranski P and Restifo NP: Essentials of Th17 cell commitment and plasticity. Blood 121: 2402-2414, 2013.

33. Harrington LE, Hatton RD, Mangan PR, Turner H, Murphy TL, Murphy KM and Weaver CT: Interleukin 17-producing CD4 ${ }^{+}$ effector $\mathrm{T}$ cells develop via a lineage distinct from the $\mathrm{T}$ helper type 1 and 2 lineages. Nat Immunol 6: 1123-1132, 2005.

34. Ye J, Livergood RS and Peng G: The role and regulation of human Th17 cells in tumor immunity. Am J Pathol 182: 10-20, 2013.

35. Guéry L and Hugues S: Th17 Cell plasticity and functions in cancer Immunity. Biomed Res Int 2015: 314620, 2015

36. Zhang JP, Yan J, Xu J, Pang XH, Chen MS, Li L, Wu C, Li SP and Zheng L: Increased intratumoral IL-17-producing cells correlate with poor survival in hepatocellular carcinoma patients. J Hepatol 50: 980-989, 2009.

37. Li Q, Li Q, Chen J, Liu Y, Zhao X, Tan B, Ai J, Zhang Z, Song J and Shan B: Prevalence of Th17 and Treg cells in gastric cancer patients and its correlation with clinical parameters. Oncol Rep 30: 1215-1222, 2013.

38. Chen WC, Lai YH, Chen HY, Guo HR, Su IJ and Chen HH: Interleukin-17-producing cell infiltration in the breast cancer tumour microenvironment is a poor prognostic factor. Histopathology 63: 225-233, 2013.

39. Su X, Ye J, Hsueh EC, Zhang Y, Hoft DF and Peng G: Tumor microenvironments direct the recruitment and expansion of human Th17 cells. J Immunol 184: 1630-1641, 2010.

40. Shan M, Yuan X, Song LZ, Roberts L, Zarinkamar N, Seryshev A, Zhang Y, Hilsenbeck S, Chang SH, Dong C, et al: Cigarette smoke induction of osteopontin (SPP1) mediates $\mathrm{T}_{\mathrm{H}} 17$ inflammation in human and experimental emphysema. Sci Transl Med 4: 117ra9, 2012.

41. Ye ZJ, Zhou Q, Gu YY, Qin SM, Ma WL, Xin JB, Tao XN and Shi HZ: Generation and differentiation of IL-17-producing CD4+ $\mathrm{T}$ cells in malignant pleural effusion. J Immunol 185: 6348-6354, 2010.

42. Li S, Li Y, Qu X, Liu X and Liang J: Detection and significance of TregFoxP3 ${ }^{+}$and Th17 cells in peripheral blood of non-small cell lung cancer patients. Arch Med Sci 10: 232-239, 2014. 
43. Liang Y, Pan HF and Ye DQ: Tc17 cells in immunity and systemic autoimmunity. Int Rev Immunol 34: 318-331, 2015.

44. Kondo T, Takata H, Matsuki $\mathrm{F}$ and Takiguchi M: Cutting edge: Phenotypic characterization and differentiation of human CD8 ${ }^{+}$ T cells producing IL-17. J Immunol 182: 1794-1798, 2009.

45. Kuang DM, Peng C, Zhao Q, Wu Y,Zhu LY, Wang J, Yin XY, Li L and Zheng L: Tumor-activated monocytes promote expansion of IL-17-producing $\mathrm{CD}^{+} \mathrm{T}$ cells in hepatocellular carcinoma patients. J Immunol 185: 1544-1549, 2010.

46. Zhang Y, Hou F, Liu X, Ma D, Zhang Y, Kong B and Cui B: Tc17 cells in patients with uterine cervical cancer. PLoS One 9: e86812, 2014.

47. Yu Y, Cho HI, Wang D, Kaosaard K, Anasetti C, Celis E and Yu XZ: Adoptive transfer of Tc1 or Tc17 cells elicits antitumor immunity against established melanoma through distinct mechanisms. J Immunol 190: 1873-1881, 2013.

48. Garcia-Hernandez ML, Hamada H, Reome JB, Misra SK, Tighe MP and Dutton RW: Adoptive transfer of tumor-specific Tc17 effector T cells controls the growth of B16 melanoma in mice. J Immunol 184: 4215-4227, 2010.

49. Nelson MH, Kundimi S, Bowers JS, Rogers CE, Huff LW, Schwartz KM, Thyagarajan K, Little EC, Mehrotra S, Cole DJ, et al: The inducible costimulator augments Tc17 cell responses to self and tumor tissue. J Immunol 194: 1737-1747, 2015.

50. Banat GA, Tretyn A, Pullamsetti SS, Wilhelm J, Weigert A, Olesch C, Ebel K, Stiewe T, Grimminger F, Seeger W, et al: Immune and inflammatory cell composition of human lung cancer stroma. PLoS One 10: e0139073, 2015.

51. Jiang G, Ma S, Wei Y, Wu Y, Yu X and Liu H: The prevalence and distribution of Th17 and Tc17 cells in patients with thyroid tumor. Immunol Lett 162: 68-73, 2014.

52. Vantourout $P$ and Hayday A: Six-of-the-best: Unique contributions of $\gamma \delta \mathrm{T}$ cells to immunology. Nat Rev Immunol 13: 88-100, 2013

53. Rei M, Pennington DJ and Silva-Santos B: The emerging protumor role of $\gamma \delta \mathrm{T}$ lymphocytes: Implications for cancer immunotherapy. Cancer Res 75: 798-802, 2015.
54. Wu P, Wu D, Ni C, Ye J, Chen W, Hu G, Wang Z, Wang C, Zhang Z, Xia W, et al: $\gamma \delta \mathrm{T} 17$ cells promote the accumulation and expansion of myeloid-derived suppressor cells in human colorectal cancer. Immunity 40: 785-800, 2014

55. Rei M, Gonçalves-Sousa N, Lança T, Thompson RG, Mensurado S, Balkwill FR, Kulbe H, Pennington DJ and Silva-Santos B: Murine CD27- $V \gamma 6^{+} \gamma \delta$ T cells producing IL-17A promote ovarian cancer growth via mobilization of protumor small peritoneal macrophages. Proc Natl Acad Sci USA 111: E3562-E3570, 2014.

56. Bystrom J, Taher TE, Muhyaddin MS, Clanchy FI, Mangat P, Jawad AS, Williams RO and Mageed RA: Harnessing the therapeutic potential of Th17 cells. Mediators Inflamm 2015: 205156 , 2015.

57. Langowski JL, Zhang X, Wu L, Mattson JD, Chen T, Smith K, Basham B, McClanahan T, Kastelein RA and Oft M: IL-23 promotes tumour incidence and growth. Nature 442: 461-465, 2006.

58. He D, Li H, Yusuf N, Elmets CA, Li J, Mountz JD and Xu H: IL-17 promotes tumor development through the induction of tumor promoting microenvironments at tumor sites and myeloidderived suppressor cells. J Immunol 184: 2281-2288, 2010.

59. Chung AS, Wu X, Zhuang G, Ngu H, Kasman I, Zhang J, Vernes JM, Jiang Z, Meng YG, Peale FV, et al: An interleukin-17-mediated paracrine network promotes tumor resistance to anti-angiogenic therapy. Nat Med 19: 1114-1123, 2013.

60. Yang B, Kang H, Fung A, Zhao H, Wang T and Ma D: The role of interleukin 17 in tumour proliferation, angiogenesis, and metastasis. Mediators Inflamm 2014: 623759, 2014.

61. Lo Re S, Dumoutier L, Couillin I, Van Vyve C, Yakoub Y, Uwambayinema F, Marien B, van den Brûle S, Van Snick J, Uyttenhove C, et al: IL-17A-producing gammadelta T and Th17 lymphocytes mediate lung inflammation but not fibrosis in experimental silicosis. J Immunol 184: 6367-6377, 2010. 